Article

\title{
Cork Core Sandwich Plates for Blast Protection
}

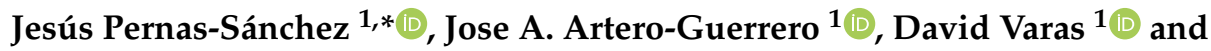 \\ Filipe Teixeira-Dias ${ }^{2}(\mathbb{D}$ \\ 1 Department of Continuum Mechanics and Structural Analysis, University Carlos III of Madrid, \\ 28911 Leganés, Madrid, Spain; jartero@ing.uc3m.es (J.A.A.-G.); dvaras@ing.uc3m.es (D.V.) \\ 2 School of Engineering, The University of Edinburgh, Edinburgh EH9 3FG, UK; f.teixeira-dias@ed.ac.uk \\ * Correspondence: jpernas@ing.uc3m.es
}

Received: 13 June 2020; Accepted: 24 July 2020; Published: 28 July 2020

\begin{abstract}
A numerical model is developed and validated to analyse the performance of aluminium skin and agglomerated cork core sandwich plates subjected to blast loads. Two numerical approaches are used and thoroughly compared to generate the blast loading: an Arbitrary-Lagrangian-Eulerian approach and the Load Blast Enhanced method. Both of the models are validated by comparing the numerical results with experimental observations. A detailed analysis of the sandwich behaviour is done for both approaches showing small differences regarding the mechanical response of the sandwich structure. The results obtained from the numerical models uncover the specific energy absorption mechanisms happening within the sandwich plate components. A new core topology is proposed, based on these results, which maximises the energy absorption capacity of the plate, keeping the areal density unchanged. A wavy agglomerated cork core is proposed and the effects of different geometrical parameters on the energy absorption are thoroughly analysed and discussed. The proposed optimised plate configuration shows an increase in the total absorbed energy of close to $40 \%$ relative to a reference case with the same areal density. The adopted optimisation methodology can be applied to alternative configurations to increase the performance of sandwich structures under blast events.
\end{abstract}

Keywords: cork; sandwich panel; blast wave; Arbitrary Lagrangian Eulerian (ALE); finite element analysis; impulsive loading; high-explosive; LS-DYNA software FEM

\section{Introduction}

Sandwich structures are used in a wide range of applications, such as in aerospace or naval structures, mostly because they are lightweight and typically have high bending stiffness. Sandwich structures have two thin outer skins and a thicker lightweight core and, because of their design, their structural and manufacturing simplicity, the potential for new applications is wide. Traditionally, the skins are either metallic or made of composite materials, such as fibre reinforced plastics (FRP), depending on the specific application and use. This allows designers to choose the skin material depending on the loading conditions that the plates are going to be subjected to. As an example, some skins are chosen for high wear resistance or high specific strength. The purpose of the core is often to provide thermal insulation but mainly to increase the moment of inertia of the component and, consequently, its bending stiffness. Common core materials are polymeric or metallic foams, or lattice structures. Moreover, these materials are also known to often exhibit high energy absorption capability. A metallic foam core, for example, is able to absorb energy (e.g., from impacts) at almost constant load and stress levels, leading to a promising structure for impulsive load (e.g., blast and shock wave) protection [1-3].

To minimise environmental cost and impact, new designs and materials should not only be energy efficient, but also recyclable or reusable. In some industrial sectors, such as the automotive 
industry, these are now mandatory requirements. The European Parliament Directive 2008/112/EC [4] enforces that:

"Vehicle and equipment manufacturers must factor in the dismantling, reuse and recovery of the vehicles when designing and producing their products. They have to ensure that new vehicles are: reusable and/or recyclable to a minimum of $85 \%$ by weight per vehicle $[\ldots]]^{\prime \prime}$

Consequently, the use of environmental-friendly materials is a major step in complying with this requirement.

The skins on sandwich plates are often exposed to impact and wear, narrowing the range of materials that can be used. However, the core is usually protected by the skins from the external environment, so the range of materials is significantly wider. Some authors have explored the use of natural materials, such as cork for core applications [5,6]. Cork and its derivatives, including agglomerated cork, have very low density and a high energy absorption capability, whilst also exhibiting a low carbon footprint for being biodegradable. These properties make agglomerated cork an excellent option for sandwich panel cores and green designs.

A number of researchers have studied the mechanical, thermal, and high strain rate behaviour of cork, and cork derivatives, such as agglomerated cork compounds, by subjecting material samples to impacts at a wide range of energies [7]. Most of these studies prove that this natural cellular material has a huge potential to be used in energy absorption applications. Sanchez-Saez et al. [8] quantified the increase of absorbed energy due to the inclusion of cork in a sandwich panel, under high velocity ballistic impacts. Sousa Martins et al. $[9,10]$ explored the use of agglomerated cork compounds as sandwich cores under blast loading, reporting on experimental results and analyses that support the observation that cork is a highly efficient energy absorbing material. Therefore, factoring in that it is a fully bio-degradable material, cork is a good candidate to be used as a liner or core in structural components, without significantly increasing their weight.

The use of sandwich components for blast mitigation has been explored by many authors, clearly demonstrating the energy absorption and protection capabilities of said structures under blast [11-14]. Hassan et al. [11] investigated the influence of varying the density of PVC cores on the blast resistance of sandwich panels, concluding that approximately $70 \%$ of the energy is absorbed by the core. Nurick et al. [13] investigated the behaviour of sandwich panels with aluminium alloy honeycomb cores under blast loading, observing that there is compromise between load transfer through the core and the increase in energy absorption. Karagiozova et al. [14] demonstrated how the permanent deflection of the skins is strongly affected by the core material properties. All of these works show the strong influence the sandwich core has, not only on the energy absorption, but also on the permanent deflection of the skins.

Some authors have explored optimising geometrical parameters of the sandwich panel in order to increase the energy absorption capability without significantly compromising the overall weight of a structure. However, these studies have almost exclusively focused on quasi-static loading. Reany et al. [15] for example, modified the topology of the core in an attempt to increase the bending stiffness and strength of the panel under uniaxial and shear buckling. Under these conditions, those authors achieved a 15\% reduction of the weight while simultaneously increasing the strength by $25 \%$. Pimenta et al. [16] introduced wavy foam cores as a liner of fibre reinforced plastics (FRP) in order to increase the energy absorption capability under uniaxial tensile loading. Using a similar approach, Arronche et al. [17] demonstrated the capability of wavy liners under drop weight impacts, with promising results in terms of weight and energy absorption.

The work here presented extends this into the dynamic regimes, by exploring and analysing the blast response of sandwich panels with aluminium skins and agglomerated cork cores. Numerical simulations of blast are performed and validated while using the experimental data available from a previous work of the authors $[9,10]$. The proposed models are shown to be crucial in the understanding of the kinematic response of sandwich plates to blast loads. Different numerical 
approaches to model the blast are used and benchmarked for computational efficiency. The main objective is to present a novel contribution for the energy absorption of sandwich plates, proposing and validating an optimised geometry for the core.

\section{Numerical Modelling}

A numerical model is developed to study the behaviour of aluminium-cork sandwich panels under blast loading. The models are validated with a thorough comparison of the obtained results to the experimental observations that were reported by Sousa-Martins et al. [10]. Post-validation, the influence of the shape, and configuration of the core on the response of the sandwich structure is studied to maximise the energy absorption capacity of the structure. The numerical models are developed in LS-DYNA [18], which is capable of reproducing the blast event in a number of different ways. To this end, two distinct approaches are explored and thoroughly compared in this work. The numerical models, the constitutive material behaviour, and the blast approximation methods used in these models are presented in the following section.

The experimental results presented by Sousa-Martins et al. [10], obtained at the blast laboratory of the Royal Military Academy (Belgium), were used to validate the numerical models. These authors used a 4-cable ballistic pendulum to study the effect of impulsive blast loads, sandwich configuration, core material, and core thickness on the behaviour of aluminium-cork sandwich panels. Two agglomerated cork compounds core were used with core densities of 200 (NL20) and $440 \mathrm{~kg} / \mathrm{m}^{3}$ (TB40). From these tests, the authors obtained the impulse transferred by the blast to the pendulum while using a laser distance sensor, as schematically shown in Figure 1. The post-impact deflection of the front and rear faces of the panels were also recorded, using a three-dimensional (3D) scanner. From these results, the authors concluded that the deformed sandwich panel presents a significant core thickness reduction. This energy absorption mechanism is more evident in the thinner sandwich plates, with thicknesses of 10 (NL20-10) and $15 \mathrm{~mm}$ (NL20-15).

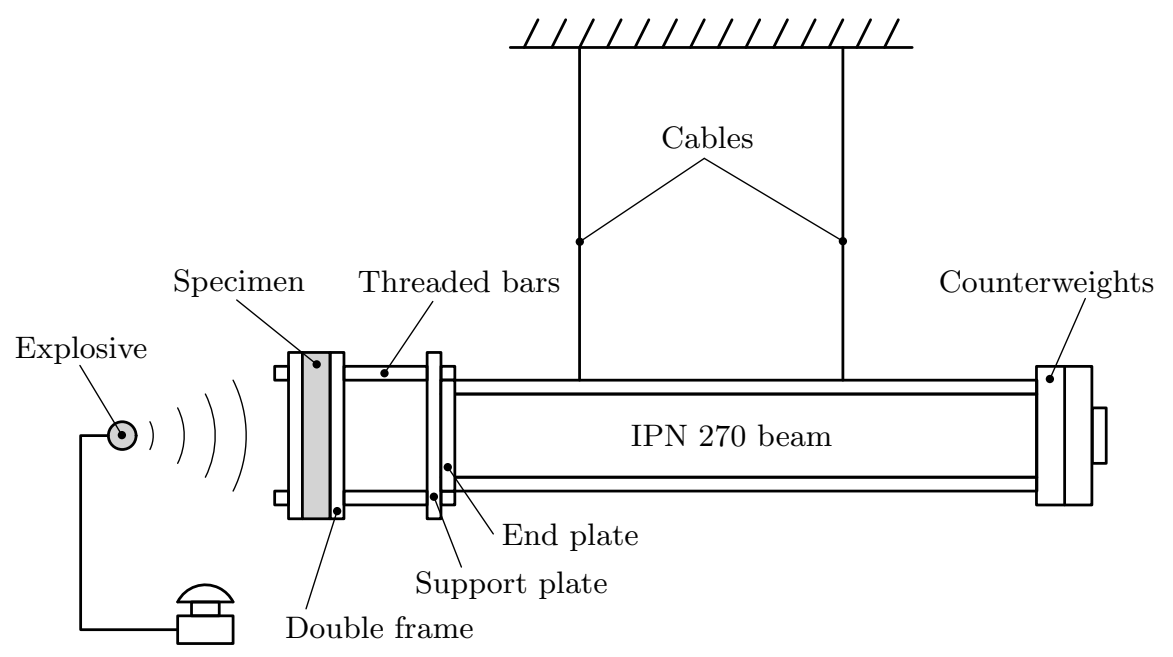

Figure 1. Experimental test apparatus (adapted from [10]) (IPN:European Standard I Beams).

The different numerical approaches developed in the present work are based on a numerical model of the complete experimental setup and test rig, and described in detail in the following paragraphs. A detailed description of the configuration of the test apparatus can be found in Sousa-Martins et al. [10].

\subsection{Ballistic Pendulum and Sandwich Structure}

The numerical model reproduces the experimental set-up, as shown in Figure 2. The ballistic pendulum, similar to the one used by Karagiozova et al. [19], consists on an IPN 270 beam of length 
$1200 \mathrm{~mm}$, denoted by 1 in Figure 2. A balancing mass of $163.5 \mathrm{~kg}$ is attached at the back and a $20 \mathrm{~mm}$ thick steel end plate at the front, denoted by 2 in the figure. This structure is connected to a $15 \mathrm{~mm}$ thick plate (3) and to the specimen support frame (5) through a set of threaded bars and nuts (4). The specimens are $320 \times 320\left[\mathrm{~mm}^{2}\right]$ sandwich panels of different thickness, which are fixed to the pendulum in the support frame, leaving an exposed area of $300 \times 300\left[\mathrm{~mm}^{2}\right]$. A Composition C-4 high explosive charge of mass $m=30 \mathrm{~g}$ is fixed and aligned with the centre of the sandwich panel, at a stand-off distance $d=300 \mathrm{~mm}$. This corresponds to a scaled distance $Z=d / \mathrm{m}^{1 / 3}=0.965 \mathrm{~m} / \mathrm{kg}^{1 / 3}$. The pendulum is suspended on four steel cables (6), although only two are shown in Figure 2 due to symmetry. The balancing mass is modelled as a lumped mass.

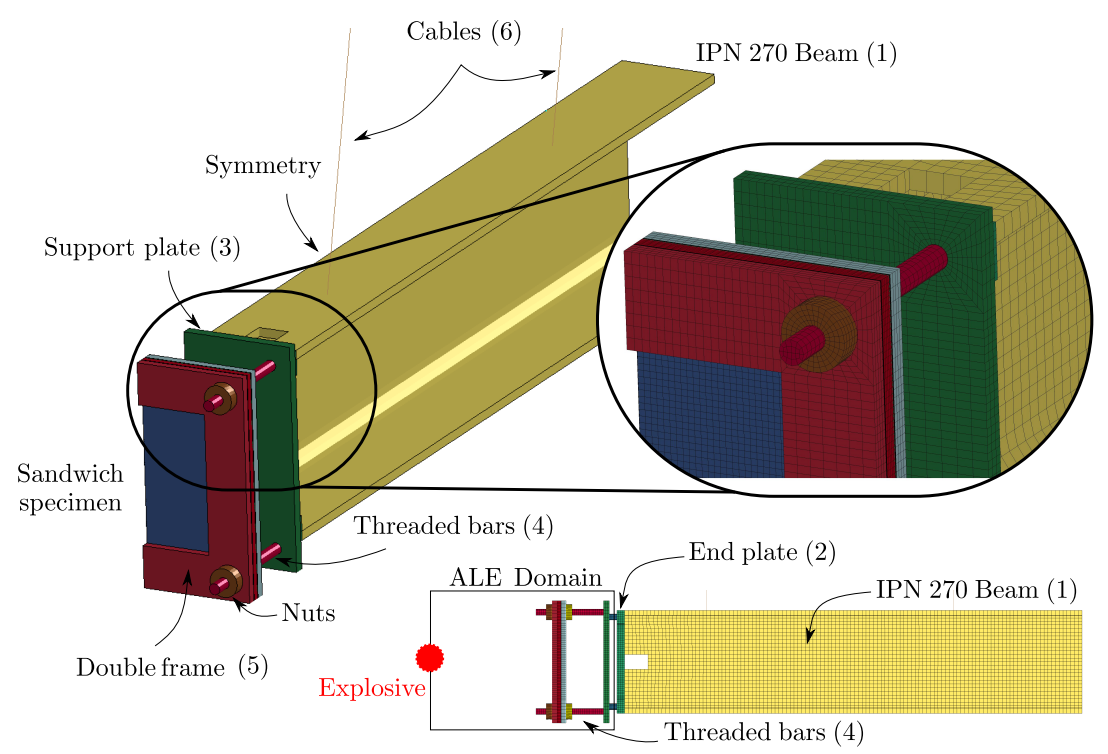

Figure 2. Numerical model of the 4-cable ballistic pendulum subjected to blast: (1) IPN 270 beam, (2) $20 \mathrm{~mm}$ end plate, (3) $15 \mathrm{~mm}$ support plate, (4) threaded connecting bars, (5) specimen support double frame, and (6) ballistic pendulum support cables.

No plastic deformation is observed after the experimental tests in any of the steel components of the ballistic pendulum. Consequently, each individual part is modelled as linear-elastic with density $\rho=7850 \mathrm{~kg} / \mathrm{m}^{3}$, Young's modulus $E=210 \mathrm{GPa}$, and Poisson ratio $v=0.3$. The model parts are connected using a tied contact algorithm. Hexahedral solid elements with reduced integration are used throughout the whole model, leading to a total of up to 107,402 elements and approximately 400k degrees-of-freedom. Table 1 lists the numbers of finite elements and degrees-of-freedom for each individual part in the ballistic pendulum model.

Table 1. Specifications of the finite element discretisation of the four-cable ballistic pendulum and specimen.

\begin{tabular}{lccc}
\hline Model Part & Elements & Degrees-of-Freedom & Number of Parts \\
\hline IPN 270 Beam (1) & 7184 & 41,382 & 1 \\
End plate (2) & 2888 & 12,330 & 1 \\
Support plate (3) & 5235 & 22,236 & 1 \\
Threaded bars (4) & 1520 & 6318 & 2 \\
Double frame (5) & 3960 & 16,800 & 2 \\
Supports & 1080 & 4380 & 2 \\
Nuts & 1160 & 5220 & 4 \\
\hline Specimen (range) & $3,375-28,125$ & $\mathbf{1 2 , 2 8 8 - 2 7 7 , 2 4 8}$ & 3 \\
\hline Total (range) & $\mathbf{2 6 , 4 0 2 - 1 0 7 , 4 0 2}$ & $\mathbf{1 3 3 , 8 7 2 - 3 9 8 , 8 3 2}$ & $\mathbf{1 6}$ \\
\hline
\end{tabular}




\subsection{Constitutive Material Modelling-Aluminium Skins}

The aluminium alloy of the sandwich plate skins is Al 5754-H22 and its behaviour is modelled while using a thermo-visco-plastic constitutive law, together with a coupled damage model. The Johnson-Cook model, which is used to achieve this, is defined by a flow stress $\sigma_{\mathrm{y}}$ with exponential strain hardening, logarithmic strain rate dependence and temperature softening. These dependencies are described by the following relation:

$$
\sigma_{\mathrm{y}}=\left[A+B\left(\bar{\varepsilon}^{\mathrm{p}}\right)^{n}\right]\left[1+C \ln \left(\dot{\varepsilon}^{*}\right)\right]\left(1-T^{*}\right),
$$

where $\bar{\varepsilon}^{\mathrm{p}}$ is the effective plastic strain, $\dot{\varepsilon}^{*}$ is the normalised total strain rate, $T^{*}=\left(T-T_{\mathrm{r}}\right) /\left(T_{\mathrm{m}}-T_{\mathrm{r}}\right)$ is the homologous temperature and $A, B, C, n$ and $m$ are material parameters. $T_{\mathrm{r}}$ and $T_{\mathrm{m}}$ are the room and melting temperatures, respectively.

An associated strain-based failure criteria is additionally used to account for damage occurring during the blast event. This criteria is defined as

$$
\varepsilon^{\mathrm{f}}=\left[D_{1}+D_{2} \exp \left(D_{3} \sigma^{*}\right)\right]\left[1+D_{4} \ln \dot{\varepsilon}^{*}\right]\left[1+D_{5} T^{*}\right],
$$

where $D_{i}$ are material parameters and $\sigma^{*}$ is the ratio of pressure $p$ to the effective stress $\sigma_{\text {eff, }}$ which is,

$$
\sigma^{*}=\frac{p}{\sigma_{\text {eff }}}
$$

Fracture occurs when the plastic strain reaches the threshold value $\varepsilon^{f}$ defined in Equation (2). The material and damage parameters for the 5754-H22 aluminium alloy are taken from the literature [20-26] and listed in Table 2.

The material compressibility (bulk behaviour) at high strain rates is accounted for by a linear polynomial equation of state that relates the pressure $p$, the density $\rho$, and the initial density $\rho_{0}$ as

$$
p=C_{1} \frac{\rho}{\rho_{0}}
$$

where $C_{1}$ is a material constant.

Table 2. Material parameters for the Johnson-Cook constitutive and damage laws, for the $\mathrm{Al}$ 5754-H22 aluminium alloy [20-26].

\begin{tabular}{llr}
\hline Parameter & Units & Value \\
\hline Density, $\rho_{0}$ & $\mathrm{~kg} / \mathrm{m}^{3}$ & 2685 \\
Young's modulus, $E$ & $\mathrm{GPa}$ & 70.33 \\
Poisson's ratio, $v$ & - & 0.3 \\
Initial yield stress, $A$ & $\mathrm{MPa}$ & 185 \\
Strain hardening coefficient, $B$ & $\mathrm{MPa}$ & 130.5 \\
Strain rate coefficient, $C$ & - & 0.003 \\
Strain hardening power constant, $n$ & - & 0.424 \\
Temperature sensitivity, $m$ & - & 2.519 \\
Room temperature, $T_{\mathrm{r}}$ & $\mathrm{K}$ & 293 \\
Melting temperature, $T_{\mathrm{m}}$ & $\mathrm{K}$ & 873 \\
Damage parameter, $D_{1}$ & - & 0.005 \\
Damage parameter, $D_{2}$ & - & 0.845 \\
Damage parameter, $D_{3}$ & - & -1.89 \\
Damage parameter, $D_{4}$ & - & 0.0897 \\
Damage parameter, $D_{5}$ & - & 7.97 \\
EOS constant, $C_{1}$ & $\mathrm{GPa}$ & 70.33 \\
\hline
\end{tabular}




\subsection{Constitutive Material Modelling_-Agglomerated Cork Core}

A non-linear elastoplastic constitutive law is used to describe the behaviour of the cork core. This is separately defined for all normal and shear stresses, similarly to the one used for honeycomb structures and described by Jackson et al. [27] and Kiliçaslan et al. [28]. To completely define the elastic component of the material behaviour, it is necessary to determine: (i) the Young's modulus $E$ and Poisson's ratio $v$ of the compacted material; (ii) the non-linear compaction stage of the material behaviour, corresponding to strains lower than approximately 0.45 in Figure 3; and, (iii) the densification region (compacted material), with an associated modulus (tangent stiffness) $E_{\mathrm{c}}$ and Poisson's ratio $v_{\mathrm{c}}$, which again corresponds to strains above 0.45 in Figure 3 . As the cork compound used in the experimental tests is agglomerated cork, the behaviour can be considered to be isotropic and the corresponding material parameters are unchanged by the loading directions. The material behaviour and parameters are those recorded and reported by Gameiro et al. [29] and Sousa-Martins et al. [10], as listed in Table 3.

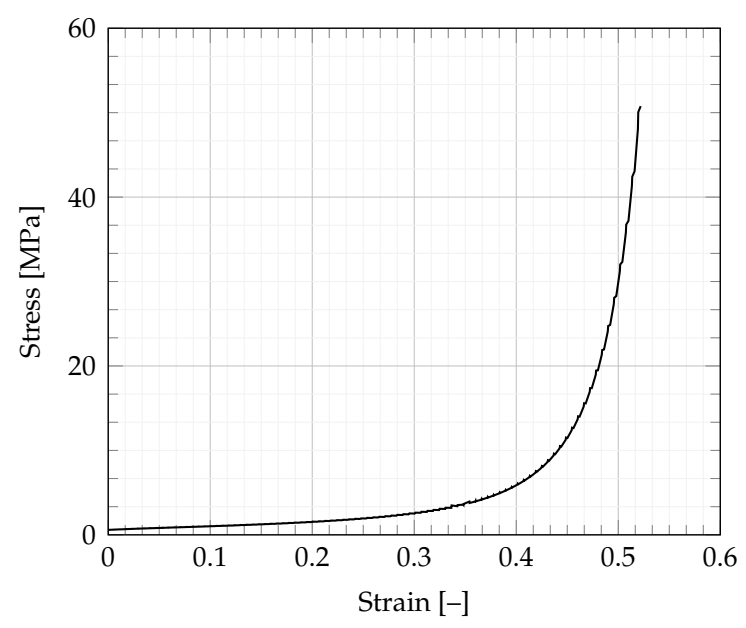

Figure 3. Mechanical behaviour of the NL20 agglomerated cork compound [10,29].

Table 3. Material parameters for the NL20 agglomerated cork compound [10,29].

\begin{tabular}{llr}
\hline Parameter & Units & Value \\
\hline Density, $\rho$ & $\mathrm{kg} / \mathrm{m}^{3}$ & 200 \\
Young's modulus, $E$ & $\mathrm{GPa}$ & 22.8 \\
Young's modulus of compacted material, $E_{\mathrm{C}}$ & $\mathrm{GPa}$ & 90 \\
Poisson's ratio of compacted material, $v_{\mathrm{c}}$ & - & 0.3 \\
\hline
\end{tabular}

\subsection{Blast Load Modelling}

Modelling the blast loading can be approached in a number of different ways and methods. Two different approximations of the blast are explored in this work: (i) the Load Blast Enhanced (LBE) method and (ii) the Arbitrary Lagrangian Eulerian (ALE) approach. Both of the methods are implemented in LS-DYNA and they are commonly used for reproducing blast events. Numerous examples can be found in the literature using either ALE [30-35] or LBE [36-42].

The Load Blast Enhanced (LBE) approach is an empirical method in which the explosive is simplified to a spherical air burst, the pressure imposed by the wave on exposed surfaces is calculated while taking the mass of the high-explosive, the distance to the target, and the angle of incidence relative to the location of the explosive into account [43]. This approach is only valid on a limited range of scaled distances $\left(0.147<Z<40\left[\mathrm{~m} / \mathrm{kg}^{1 / 3}\right]\right)$ [44]. The work reported here is covered by this range as $Z=0.965 \mathrm{~m} / \mathrm{kg}^{1 / 3}$. One of the main advantages of this approach is the low computational effort required to define the blast, because the air domain is not explicitly modelled. Conversely, 
as a simplification, the approach does not take into account effects, such as shadowed surfaces, reflected waves, etc. The blast is uniquely defined by the mass and location of the explosive, and the surfaces onto which the wave will impact.

The Arbitrary Lagrangian Eulerian (ALE) approach explicitly defines the high-explosive, including its shape, the surrounding air, and the coupling between the fluids and the structure. This significantly increases the computational cost, but takes into account all possible reflections and interactions between the shock waves from the detonation and structures. To this end, it is necessary to define not only the high-explosive material and its equation of state, but also the behaviour of the surrounding air. The air domain must involve the structures that will be subjected to the blast. This region is shown in Figure 2 and labelled as ALE domain. This domain has a volume $200 \times 400 \times 450\left[\mathrm{~mm}^{3}\right]$ and an element size of $4 \mathrm{~mm}$ was used, which resulted in a total of $5.65 \times 10^{5}$ elements. The external surfaces of this volume are defined as non-reflecting, following the observations and recommendations of Artero-Guerrero et al. [30].

The explosive is a $16.5 \mathrm{~mm}$ radius sphere and its behaviour is described by a high-explosive material using a Jones-Wilkins-Lee (JWL) equation of state (EOS). The release of chemical energy from the detonation is accounted for in this EoS, both from the resulting compression and the programmed detonation $[18,45]$. The former defines the detonation when the compression in the material reaches the Chapmant-Jouget pressure $\left(P_{\mathrm{CJ}}\right)$, whilst the latter defines the initial detonation time as a function of the detonation velocity $D$ and the location of the detonation point [46]. The JWL model defines the pressure as

$$
p=A\left(1-\frac{\omega}{R_{1} v}\right) e^{-R_{1} v}+B\left(1-\frac{\omega}{R_{2} v}\right) e^{-R_{2} v}+\frac{\omega \bar{E}}{v}
$$

where $A, B, R_{1}, R_{2}$, and $\omega$ are material constants, $v=\rho_{0} / \rho$ is the ratio of the initial to the current densities (i.e., the relative volume) and $\bar{E}$ is the internal specific energy (i.e., per unit volume).

Air is assumed to behave as an ideal gas and its equation of state can, thus, be defined as

$$
p=(\gamma-1) \frac{\rho}{\rho_{0}} \bar{E}
$$

where $\gamma$ is the ratio of specific heats $\left(\gamma=c_{\mathrm{p}} / c_{\mathrm{V}}\right)$. The material properties of the air are also listed in Table 4 and were obtained from the literature $[30,47]$.

Table 4. Material properties for the high-explosive (C4) and air used in the MM-ALE numerical models [30,47].

\begin{tabular}{llrr}
\hline Property & Units & Explosive (C4) & Air \\
\hline$\rho_{0}$ & $\mathrm{~kg} / \mathrm{m}^{3}$ & 1601 & 1.23 \\
$\bar{E}$ & $\mathrm{GJ} / \mathrm{m}^{3}$ & 7.0 & $2.58 \times 10^{-4}$ \\
$D$ & $\mathrm{~m} / \mathrm{s}$ & 8193 & - \\
$P_{\mathrm{CJ}}$ & $\mathrm{GPa}$ & 28.0 & - \\
$A$ & $\mathrm{GPa}$ & 609.8 & - \\
$B$ & $\mathrm{GPa}$ & 12.95 & - \\
$R_{1}$ & - & 4.5 & - \\
$R_{2}$ & - & 1.4 & - \\
$\omega$ & - & 0.25 & - \\
$\gamma$ & - & - & 1.4 \\
\hline
\end{tabular}

\subsection{Mesh Convergence Analysis}

All of the components of the sandwich plate model (skins and core) use solid elements, with five elements along the thickness direction. A detailed convergence analysis was done on a simplified model which did not include the ballistic pendulum. This is supported by observations that the numerical results are not significantly influenced by the discretisation of the elastic ballistic pendulum components. The boundary conditions $(\mathrm{BC})$ on the sandwich plate are similar to those 
imposed by the actual clamping system. However, the overall displacement in the sandwich is slightly overestimated in comparison with the measured experimental displacement. The mesh convergence study can still be achieved despite this difference.

The average displacement history of the centre of the sandwich panel is shown in Figure 4a, for various mesh densities between 3375 and 84,375 elements. All of the finite element meshes are structured and regular, with a minimum of 5 integration points along the thickness. The example case shown corresponds to the NL20-10 sandwich plate, and is selected because the average displacement of the sandwich plate shows significant fluctuations during the blast loading. Initially, the displacement increases steeply in all meshes at almost constant slope. The maximum displacement, however, is lower for the coarser meshes. As the element size decreases the simulations clearly converge to a maximum value, with very similar trends. Figure $4 \mathrm{~b}$ shows the final displacement of the rear and front faces of the sandwich plate as a function of the total number of elements.

It can be clearly observed that the influence of the discretisation on the results vanishes for mesh densities above $0.1 \times 10^{5}$ elements. Additionally, it should be considered that the mesh density has a strong impact on the computational effort and, consequently, a mesh of $2 \times 2\left[\mathrm{~mm}^{2}\right](45 \times 45 \times 5)$ on the plane on the plate, corresponding to 37,500 elements, is chosen as the ideal compromise between the quality of the results and computational efficiency.

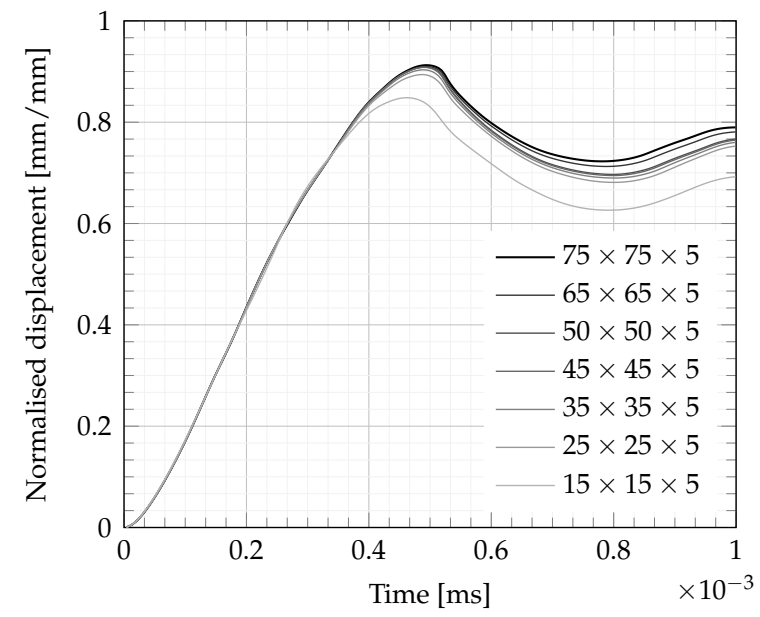

(a)

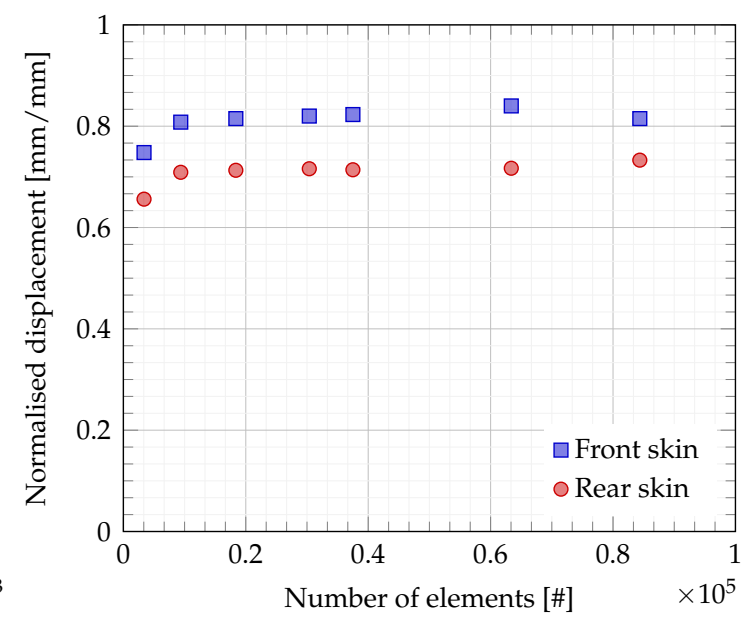

(b)

Figure 4. Mesh convergence analysis for the NL20-10 sandwich plate: (a) normalised displacement history and (b) normalised displacement convergence, for all tested discretisations (see Table 1 for mesh parameters).

\section{Validation and Analysis}

The proposed numerical models are validated and results analysed and compared with the experimental observations. Additionally, the LBE and ALE approaches for blast simulations are compared in terms of the results and computational efficiency. Numerical models should accurately replicate the physics of the problem and accurately predict experimental observations and measurements. The experimental results include the impulse transmitted to the ballistic pendulum and the final deflection of the sandwich skins $[9,10]$.

The impulse calculated from the measured displacement and initial velocity of the pendulum is compared with the results obtained in the numerical simulations. The experimental results register the global impulse transmitted to all surfaces of the pendulum exposed to the blast wave. This naturally includes the sandwich plate and the supporting frames. Consequently, the impulse obtained in the numerical simulations takes into account all of these surfaces. The transmitted impulse for the two analysed cases (NL20-10 and NL20-15 with 10 and $15 \mathrm{~mm}$ of core cork thickness, respectively) are 
listed in Table 5, for the numerical and the experimental tests. The difference in impulse between the experimental tests NL20-10 and NL20-15 are negligible (0.1\%), because the mass of explosive is kept constant and the exposed surfaces are identical. The numerical simulations also predict small differences between specimens of different thickness (4.3\% in ALE and $0.2 \%$ in LBE).

Table 5. Experimental and numerical impulses transmitted to the ballistic pendulum.

\begin{tabular}{cccccc}
\hline & Experimental [Ns] & ALE [Ns] & Error [\%] & Load Blast Enhanced (LBE) [Ns] & Error [\%] \\
\hline NL20-10 & 15.87 & 16.98 & 7.0 & 17.84 & 12.4 \\
NL20-15 & 15.85 & 16.26 & 2.6 & 17.89 & 12.9 \\
\hline
\end{tabular}

Good agreement is observed between the experimental and the predicted transmitted impulse (with both the LBE and the ALE numerical approaches), with errors below 7\% for the ALE and below $13 \%$ for the LBE approach, as listed in Table 5. Both methods overestimate the impulse produced by the explosion, although LBE tends to be higher. This behaviour is probably related to the fact that LBE does not model the negative phase of the blast wave. Although this phase is small in magnitude when compared to the overpressure peak, it can lead to the small differences in the observed impulse. It is assumed that both approaches adequately reproduce the overpressure pulse of the blast, as the impulse is a consequence of the pressure from the blast wave on the exposed surfaces.

A thorough analysis of the blast response of the plates is reported in Table 6. This includes the experimental and numerical deflection of the front and back skins, measured at the geometrical centre of the plates. Due to the expected compression of the cork, there is a differential in the displacement of both skins, that is, the front skin displacement is consistently larger than that of the rear skin. This effect is reproduced by the proposed numerical model, albeit only for the NL20-10 core. It should be noted that the rear skin experimental displacement of the plate with the NL20-15 core had to be discarded due to debonding from the cork core. All other numerical results show very good agreement with the experimental observations. The thinner sandwich plate (10 mm core thickness), with lower bending stiffness, has higher deflection in both skins when compared to the thicker plate (15 mm core thickness), as expected. As the aluminium skins on all specimens have the same thickness, the different behaviour is due to the changes in the thickness of the core.

Table 6. Experimental and numerical displacements to the ballistic pendulum.

\begin{tabular}{lcccccc}
\hline & Sandwich skin & Exp [mm] & ALE [mm] & Error [\%] & LBE [mm] & Error [\%] \\
\hline \multirow{2}{*}{ NL20-10 } & Front & 5.63 & 5.28 & 6.2 & 5.52 & 1.9 \\
& Back & 5.01 & 4.68 & 6.6 & 4.71 & 5.9 \\
\hline \multirow{2}{*}{ NL20-15 } & Front & 5.13 & 5.15 & 0.4 & 5.49 & 7.0 \\
& Back & 5.22 & 4.36 & - & 4.40 & - \\
\hline
\end{tabular}

These observations and conclusions about the impulse and the front and rear sandwich deflection ensure that both blast modelling approaches (ALE and LBE) are capable of reproducing the physics of the blast event under the defined conditions and can, therefore, be used to analyse the structural behaviour of the sandwich plates in more depth.

From the numerical simulations it is possible to determine how impulse evolves during the blast. The results presented in Figure 5a show the numerical values of the impulse on the exposed surfaces of the four-cable ballistic pendulum. The total impulse and experimental measurements are also displayed for comparison. It should be noted that the ALE approach predicts the time of arrival of the wave to be approximately $200 \mu \mathrm{s}$, which coincides with the time of arrival of the blast wave to the first exposed surface (i.e., the rig-front in Figure 2). At almost the same time, the wave impacts the front skin of the sandwich plate; note that only $12 \mathrm{~mm}$ separate both surfaces. The remaining exposed surfaces receive the impact of the blast wave instants later. With the LBE approach, only the directly 
exposed surfaces of the rig and sandwich plate receive impulse-all other surfaces are shadowed by these, as shown in Figure 5. The main contribution to the total impulse is the one on the directly exposed surfaces and, thus, the LBE method is capable of accurately predicting the transmitted impulse. A similar analysis and conclusion can be drawn from the evolution of the impulse on the NL20-15 sandwich plate.

The ALE and the LBE approaches both predict a higher impulse on the frontal surface of the rig than on the sandwich. Although the rig is not in the direct line of the blast wave, it has a higher exposed surface- $53 \%$ more than the sandwich plate specimen - which leads to a higher transmitted impulse. However, the pressure is higher on the surface of the sandwich panel as the blast wave hits it orthogonally. This is shown in Figure 5b. The numerical model using the LBE method shows higher pressure on the sandwich, which is a likely explanation for the higher observed deflections, as listed in Table 6. However, it should be noted that the pressure pulse shape is similar with both numerical approaches.

The sudden increase of the impulse at approximately $0.2 \mathrm{~ms}$ is consistent with the time of arrival of the blast wave and it is recorded similarly in both approaches. However, the LBE method predicts a constant value of impulse afterwards, while the ALE method shows impulse fluctuations. These differences are caused by (i) a misrepresentation of the negative phase of the blast wave by the LBE approach, as shown in Figure 5b, and (ii) blast wave reflections on other surfaces, an effect that can only be reproduced by the ALE model.

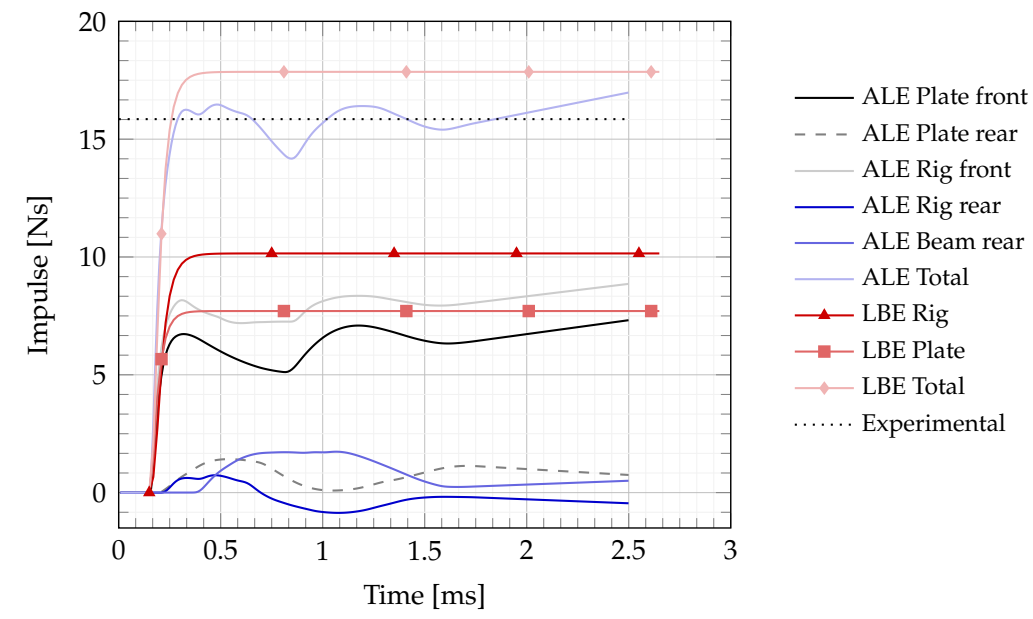

(a) Impulse

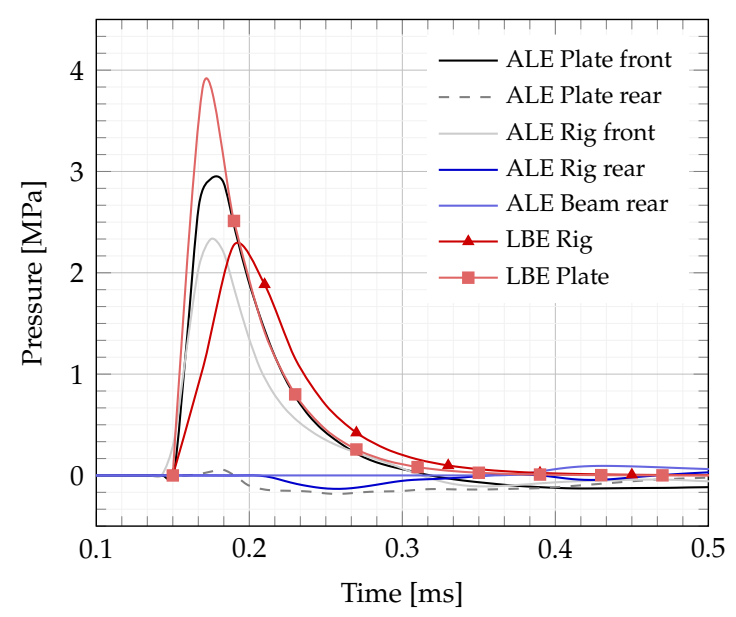

(b) Pressure

Figure 5. Impulse and pressure-time histories for NL20-10 specimen in LBE numerical model. 
However, the LBE method predicts a constant value of impulse, while the ALE method shows impulse fluctuations. This is caused by (i) a misrepresentation of the negative phase of the blast wave by the LBE approach, as shown in Figure 5, (ii) blast wave reflections on secondary surfaces, an effect that can only be reproduced by the ALE model, and (iii) blast wave clearing effects.

The fluctuations on the impulse on the shadowed surfaces calculated with the ALE approach and shown in Figure 5a, can be explained through an incremental analysis of the interaction of the blast wave with the pendulum. This is shown in Figure 6. Snapshots at time increments between 0.14 and $0.42 \mathrm{~ms}$ show the edge of the test rig/sandwich. No overpressure is observed at the back of the specimen ahead of the impact of the wave on the structure. However, a pressure vortex is formed at the edge of the rig/specimen when the blast reaches the corner of the specimen. This is known as the blast wave clearing effect [48]. As a result, the pressure wave is diffracted around the target edge causing a reduction in the pressure and impulse. A consequence of this effect is also that pressure wave impacts the support plate (see label 3 in Figure 2), and it is afterwards reflected at the rear of the specimen. This causes the negative impulse on the shadowed surfaces. Although the LBE method is not capable of reproducing this phenomenon and the blast wave clearing effects, its relative contribution to the total impulse is small when compared to the other parts of the test rig, including the specimens, and can thus be neglected. In the analysis of complex armour or protection systems with a similar configuration to the one studied (with free edges or shadowed surfaces); however, blast wave clearing effects and their structural implications should be considered.

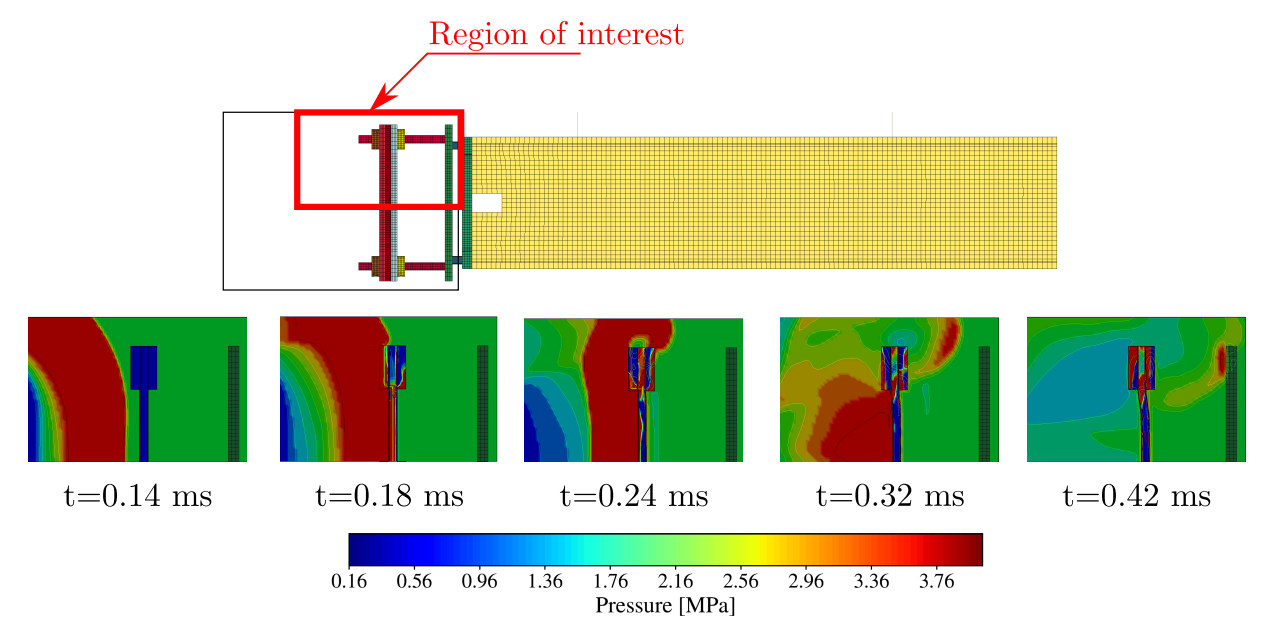

Figure 6. Blast wave evolution in NL20-10 specimen for the ALE simulation.

The structural response of the sandwich plate to the impact of the blast wave can be separated in three distinct stages, namely [10]:

- Stage I-This is the stage where the blast wave is generated and collides with the structure. The high-explosive detonates and generates a blast wave (see Figure 6), which imposes an initial velocity to the front skin of the sandwich plate upon hitting it. Although this velocity cannot easily be experimentally measured, this can be obtained from the numerical simulations for the duration of the blast. The results presented in Figure

reffig:VelocityNodesa,b show the velocity of all the nodes through the thickness of the centre of the sandwich. Figure $7 \mathrm{~b}$ shows the kinematics of the front and rear faces of the plate on the initial stages of the impact. In these images, the velocity of the front plate has been represented in blue, the rear plate in red; whereas, in grey, the velocity of different points equally distributed through the thickness have been plotted.

- Stage II-After a short delay ( $t \approx 10 \mu$ s in the current model) the rear face of the sandwich starts to move. Due to the differential in velocity of the front and rear face of the sandwich, however, core compression continues during this stage. Before the end of this stage, the maximum 
difference in velocities between the front and the rear faces is reached, corresponding to the maximum compression rate of the sandwich core. Core compression is the dominating energy absorption mechanism in this stage.

- Stage III-At $t \approx 85 \mu$ s (in the current model) the front and rear surfaces of the sandwich panel move with similar velocity, i.e., the core no longer compresses and the main global deformation mechanism is bending-stretching. From this moment onward, the velocities of the nodes decay, reaching 0 at approximately $500 \mu$ s in the current model.

As described above, the two main energy absorbing mechanism in the system are the compression of the plate core and the bending-stretching of the sandwich plate. To isolate and analyse these two effects, the out-of-plane (i.e., through-thickness) strain, which directly relates to core compression, and the in-plane strain, which relates to bending and stretching, are shown in Figure 8. Compression initiates when the blast wave impacts the front skin and terminates at $\approx 75 \mu$ s for the NL20-10 specimen and $\approx 85 \mu$ s for the NL20-15 specimen. These match the instants when the velocity of the nodes collapses, at the start of Stage III (see Figure 7b). Compression of the agglomerated cork core is not homogeneous, which is a consequence of the dynamic nature of the loading. When comparing the two samples, with thicknesses of 10 and $15 \mathrm{~mm}$, in Figure $8 \mathrm{a}, \mathrm{b}$, respectively, it can be seen that compression closer to the front face is higher for the thicker plate, namely in the first 5 elements through thickness.

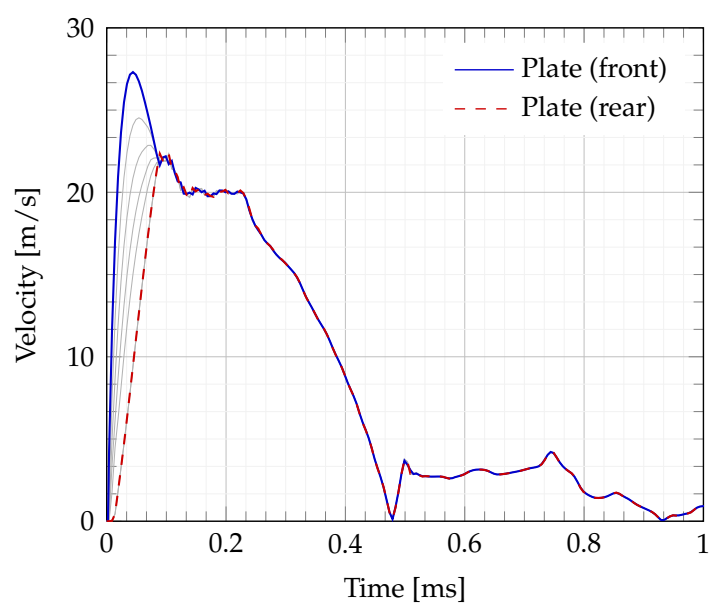

(a)

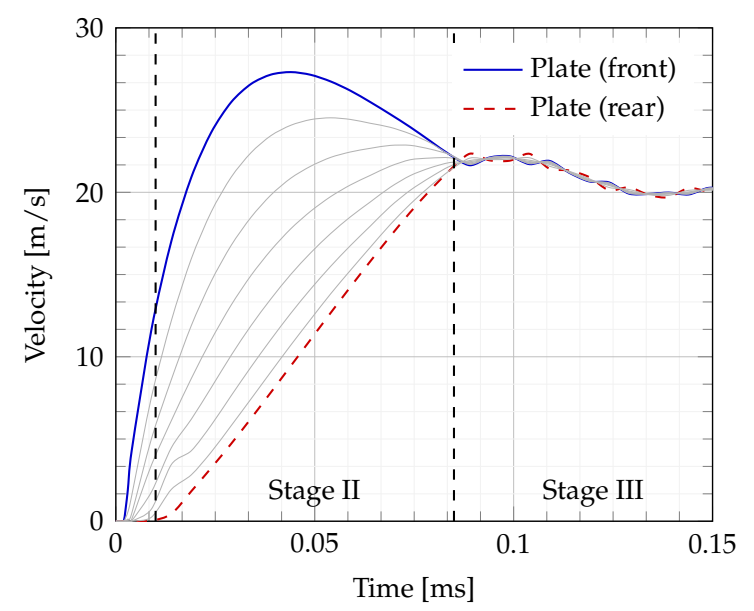

(b)

Figure 7. Kinematics of the NL20-15 sandwich plate as obtained with the LBE numerical model: (a) velocity profile of the central nodes along the thickness of the sandwich plate (grey), highlighting the front face (blue) and rear face (red) of the specimen, (b) initial stages $(0<t<0.14)$ of the velocity profile of the central nodes (dashed lines indicate separation of stages).

Taking into account that the element size is the same in both cases, it can be concluded that energy absorption is higher in the NL20-15 sandwich plate. It can also be observed that the two elements closer to the rear face in the NL20-15 specimen experience very low compression. This observation is consistent with the experimental evidence reported by Sousa-Martins et al. [10], who concluded that for sandwich plates with cores thicker than $20 \mathrm{~mm}$, the plate behaves as a monolithic plate and the compression becomes less prominent.

The in-plane strain $\varepsilon_{x}$ on the sandwich plate is shown in Figure $8 \mathrm{c}, \mathrm{d}$ for both specimens. In pure bending, the in-plane strain $\varepsilon_{x}$ at the plate surface should be equal in magnitude and with opposite sign - either compression or tension-and change linearly through thickness. In pure stretching, however, strains should be equal and positive along the thickness. The main difference is the mixicity of the different induced strain mechanisms. The NL20-10 case reaches positive values of strain earlier than in the NL20-15 case, so that the stretching mechanism seems to be more important in the thinner cases. 
The results presented in Figure 9 show the evolution of the kinetic and internal energies for the individual components of the sandwich plate (skins and core), for core thicknesses of 10 and $15 \mathrm{~mm}$, corresponding to specimens NL20-10 and NL20-15, respectively.

When the blast wave collides with the front skin, its kinetic and internal energy increases and the cork core is compressed. The back skin then starts to deform and its kinetic energy also increases. When the maximum kinetic energy is reached (corresponding to the maximum velocities in Figure 7), the cork compression ends but its internal energy keeps increasing. From this instant onward, the energy is mainly absorbed by bending and stretching (Stage III). As the compressibility of the skins can be neglected, internal energy is mainly absorbed by bending-stretching. Once the overall bending process finishes, the internal energy accumulated in the cork core and skins plateaus, at approximately $1 \mathrm{~ms}$. The total energies absorbed by both configurations can be obtained from Figure 9. The NL20-10 specimen absorbs $57.4 \mathrm{~J}$ (52.2 J core, $2.1 \mathrm{~J}$ upper skin, 3.1 J lower skin), while the NL20-15 specimen absorbs $58.9 \mathrm{~J}$ ( $54.9 \mathrm{~J}$ cork, $1.9 \mathrm{~J}$ upper skin, $2.1 \mathrm{~J}$ lower skin). The increase on the cork thickness leads to a negligible improvement in energy absorption (of only $1.5 \mathrm{~J}$ ) for a $50 \%$ increase of the weight. Therefore, the energy absorption optimisation process should focus on core topology instead of cork thickness.

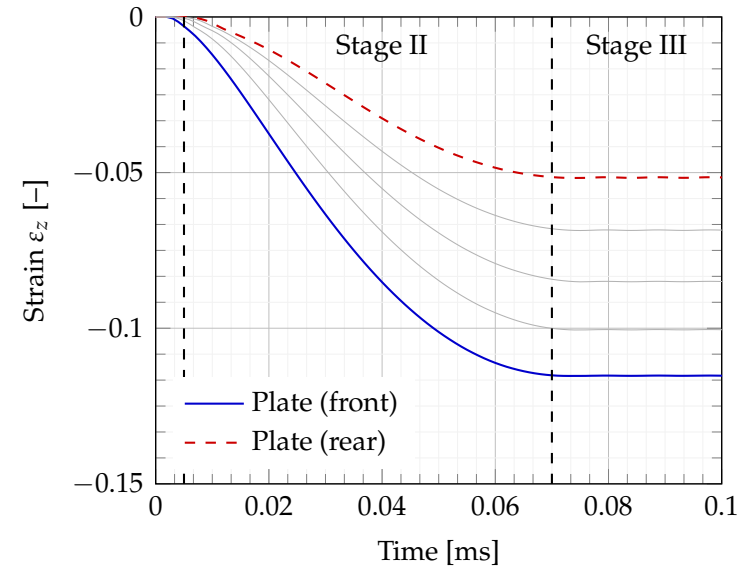

(a) NL20-10

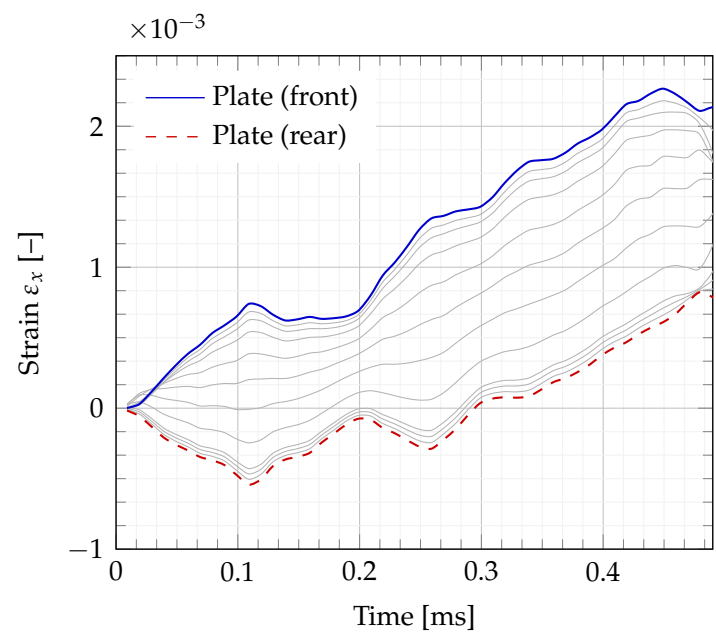

(c) NL20-10

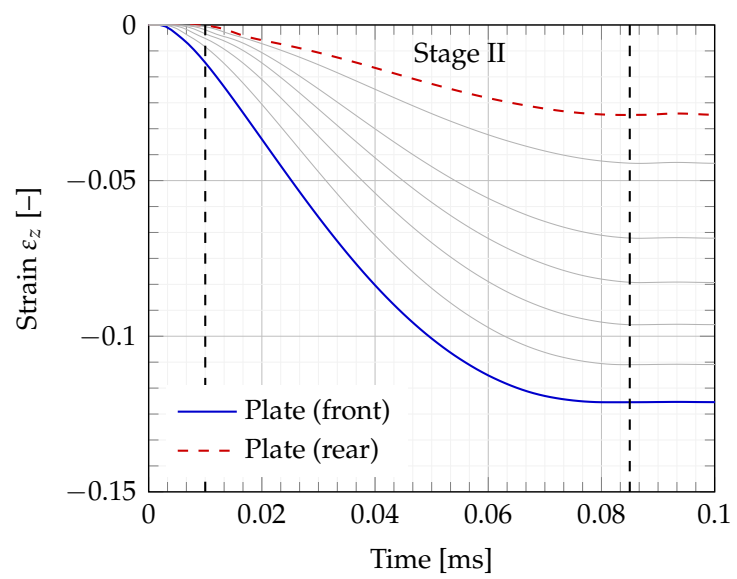

(b) NL20-15

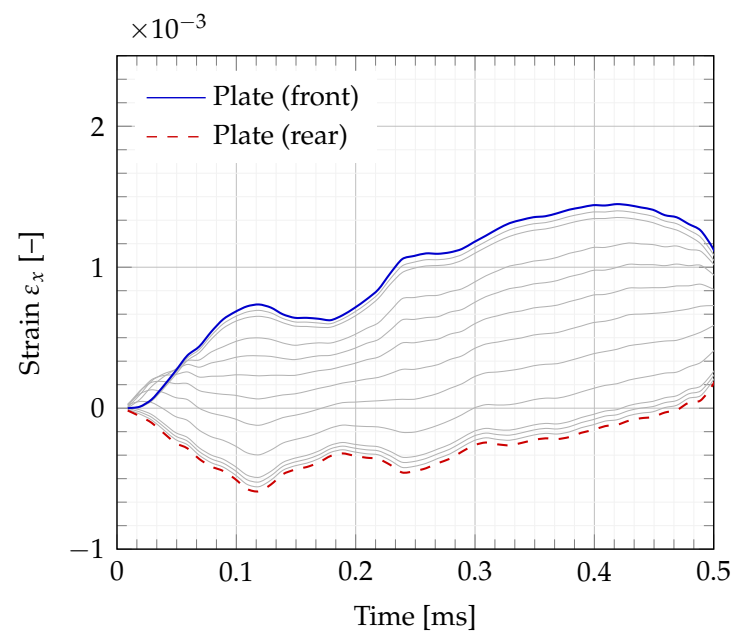

(d) NL20-15

Figure 8. Sandwich plate strain profiles: $(\mathbf{a}, \mathbf{b})$ through-thickness strain $\varepsilon_{z}$ for the NL20-10 and NL20-15 specimens, respectively, showing evidence of core compression (only the cork elements are presented because no compression is observed in the aluminium); and (c,d) in-plane strain $\varepsilon_{x}$ for the NL20-10 and NL20-15 specimens, respectively, showing evidence of bending-stretching (dashed line shows separation between both regimes). 
The fractions of energy absorbed by each mechanism are also shown in Figure 9, showing that both are relevant in the absorption process. As expected, more energy is absorbed by compression for the thicker plate (48.6\% compared to $38.9 \%$ in the NL20-10 specimen). Bending and stretching is less important but albeit still relevant. This is supported by the results in Figure 8. The cork core absorbs more energy than the skins, by a factor of 25 , for both core thicknesses. This is similar to the observations that were reported by Hassan et al. [11]. As the thickness of the core increases the differences between the energy absorption of the skins diminish, since the thicker core promotes more similar deflection of both skins.

In terms of numerical efficiency, the computational time for the ALE model is approximately four times longer than for the LBE (1183 s/CPU for the ALE and $276 \mathrm{~s} / \mathrm{CPU}$ for the LBE). This is due to the higher number of elements and, consequently, degrees-of-freedom, and the additional advection step during the ALE integration. Although the LBE method cannot capture the impulse on shadowed surfaces or wave reflections, however, the main contribution of the exposed surfaces is well captured and it can be used for design purposes.

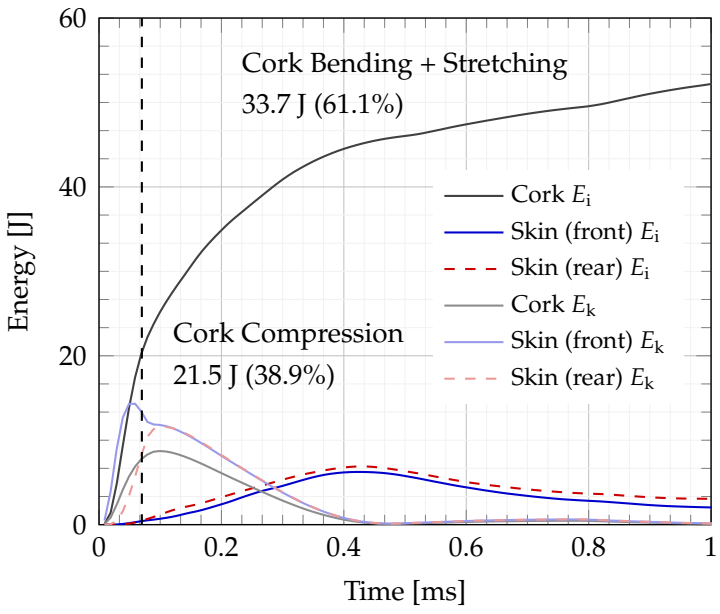

(a)

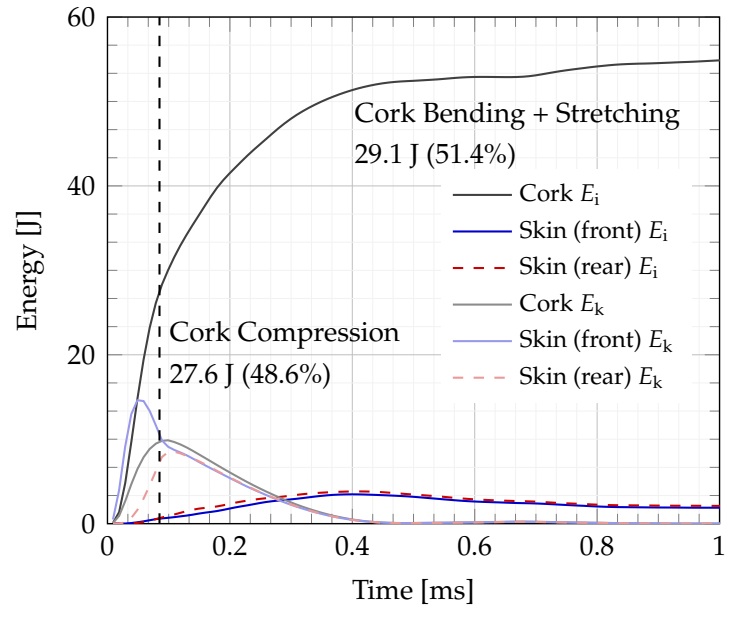

(b)

Figure 9. Kinetic energy $E_{\mathrm{k}}$ and internal energy $E_{\mathrm{i}}$ for the individual components of the sandwich plate (skins and core), for core thicknesses of (a) $10 \mathrm{~mm}$ (NL20-10) and (b) $15 \mathrm{~mm}$ (NL20-15). Dashed line indicates separation between core compression and core bending and stretching.

\section{Core Topology Optimisation}

From the analyses and conclusions in the previous sections, it is clear that the core has the most significant role in the energy absorption process: it absorbs approximately $90 \%$ of the energy, contributing with less than $30 \%$ of the mass of the structure. Consequently, the most efficient way to increase energy absorption and blast performance of the sandwich plate is to optimise the core. However, for armour and protection applications, increasing the efficiency of the sandwich panel should be done by increasing both the energy absorption of the skins and core, whilst keeping the areal density unchanged.

This section discusses a number of approaches that are designed to maximise the energy absorption of the plate, based on numerical simulations, namely by changing the configuration of the core. This follows the conceptual ideas presented by a number of other authors [15-17,49]. However, in these works-which include a wavy core between skins-the energy absorption is increased under quasi-static loading.

A set of sinusoidal core shapes with flat aluminium plane skins were chosen to promote an increase of the energy absorption under blasts event. Figure 10 shows an example. This geometry is also chosen due to its relative ease of manufacture and assembly, because only the core needs to be modified. 
The optimum configuration was found by optimising the geometrical amplitude and frequency of the sinusoidal wave defining the shape of the core. The centre line of the core is defined by $z=A \cos (\omega x / W)$, where $z$ is the out of plane coordinate, $A$ is the wave amplitude, $W$ is the width of the plate (in this case $W=100 \mathrm{~mm}$ ), $\omega=2 \pi f$ is the angular frequency, and $f$ the frequency. As $f$ increases, the distance between the peaks $(w=W / f)$ is reduced, as shown in Figure 10. The particular combinations of amplitude and frequency tested are listed in Table 7 . The areal density of the panel was kept constant to isolate the energy absorption as the parameter being optimised. Additionally, the core geometrical amplitude was kept between the thickness of the NL20-10 and NL20-15 plates, in order to ensure consistency with the validation analyses described in previous sections.

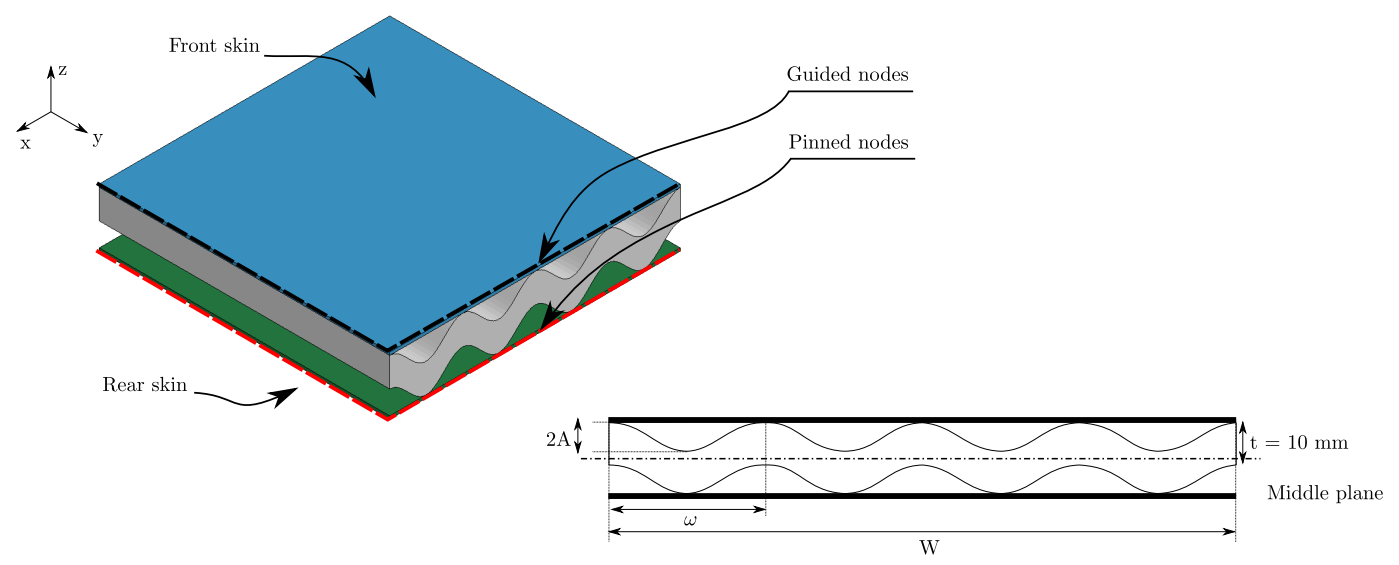

Figure 10. Sandwich panel with sinusoidal core and generic dimensions.

To maximise computational efficiency, the above simulations were simplified and only the Load Blast Enhanced method was used. Moreover, the numerical model, as shown in Figure 10, only takes into account the free span of the sandwich. Boundary conditions representative of the experimental testing rig were implemented, where the edge of the rear skin was fixed by restricting displacements but not rotations. Additionally, the nodes on the edges of the front skin are guided-their movement is only constrained along $x$ and $y$. The materials models and LBE approaches are the same as described in the previous sections and a reference case is included for comparison.

Table 7. Geometric parameters (amplitude and frequency) for the core optimisation analysis (the reference case corresponds to the flat core).

\begin{tabular}{lccr}
\hline ID & $\begin{array}{c}\text { Amplitude } A \\
{[\mathrm{~mm}]}\end{array}$ & Frequency $f$ & $\begin{array}{r}\text { Frequency } \omega \\
\text { [mm] }\end{array}$ \\
\hline Reference & 0 & - & - \\
A1-f2 & 1 & 2 & 50.27 \\
A1-f4 & 1 & 4 & 25.13 \\
A1-f8 & 1 & 8 & 12.57 \\
A2-f2 & 2 & 2 & 50.27 \\
A2-f4 & 2 & 4 & 25.13 \\
A2-f8 & 2 & 8 & 12.57 \\
A4-f2 & 4 & 2 & 50.27 \\
A4-f4 & 4 & 4 & 25.13 \\
A4-f8 & 4 & 8 & 12.57 \\
\hline
\end{tabular}

The results presented in Figure 11a,b show the kinematics of the plates during the blast impact. These figures show the velocities of the central nodes on the front and rear face sheets for the simulations listed in Table 7. Figure 11a shows the results for different amplitudes of the sinusoidal core shape with constant frequency $f=4$, compared to the reference case. It is observed that the front 
node shows a velocity peak for all amplitudes, which is higher than the reference case. Although the trends are similar in all cases, a slight increase of the velocity with the amplitude can be seen. This is explained because the sinusoidal shape delays the contact between the core and the rear skin, allowing for the front skin to move with higher velocity. It also increases the time of arrival of the impact to the rear skin. These differences delay the stationary velocity stage in which both skins have the same velocity and, thus, the core and the front skin are allowed to deflect more when compared to the reference case.

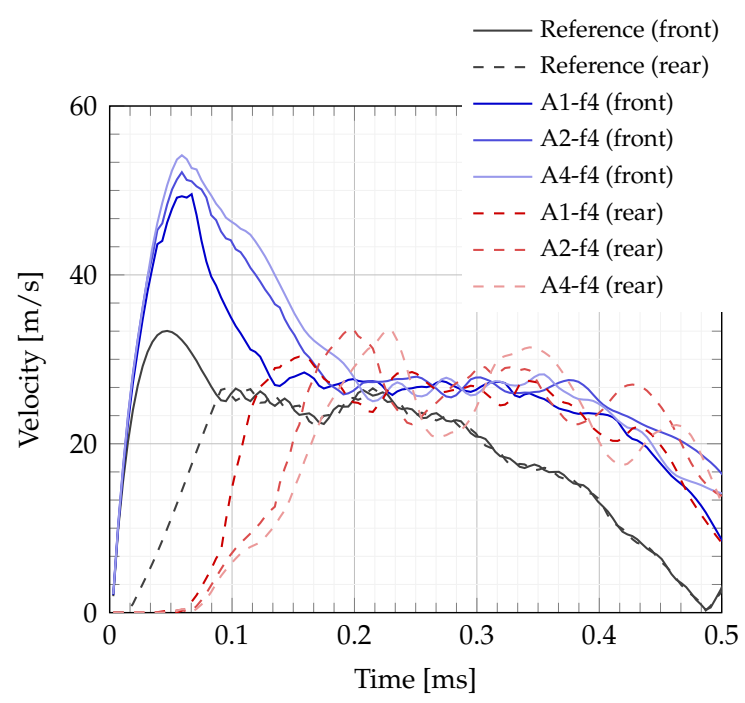

(a) Amplitude

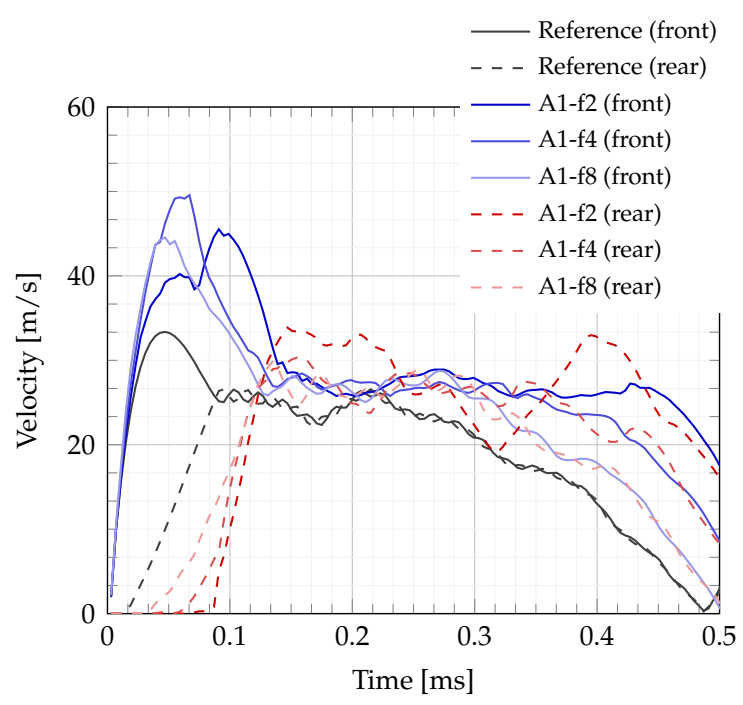

(b) Frequency

Figure 11. Sandwich plate kinematics for different core shape parameters: (a) effect of the sinusoidal core amplitude for a constant geometrical frequency $f=4$, and (b) effect of the geometrical frequency for a constant amplitude $A=1 \mathrm{~mm}$.

The results presented in Figure 11b, on the other hand, show the kinematics of the plates as a function of the frequency of the core shape for a constant amplitude $A=1 \mathrm{~mm}$. The kinematic behaviour is similar to the previous cases, and the peak velocity of the front skin reaches similar order of magnitude values. However, the increase of the geometrical frequency reduces the time of arrival of the impact to the rear skin, albeit with similar accelerations. As the frequency increases, the free distance for the core to move diminishes, allowing for the rear skin to initiate its motion sooner.

The changes in kinematic and mechanical behaviour described above lead to differences in the energy absorption mechanisms within each sandwich plate. Figure 12 shows the total absorbed energy for each combination of geometrical frequency and amplitude. The results presented in Figure 12a show a clear increase in the energy absorption with the amplitude, visible for the whole range of analysed frequencies. Additionally, the energy absorbed by the sandwich plate is consistently higher than in the reference case. These observations are supported by the differences on velocities shown in Figure 11. Both energy absorption mechanisms-cork compression and overall bending and stretching-contribute to this. An inverse trend can be observed in Figure 12b, where the absorbed energy decreases with the increase of the geometrical frequency, regardless of the amplitude. The rear skin starts to move sooner, as the frequency increases, and therefore Stage III initiates earlier in the process, while cork compression ends prematurely, as discussed above. 


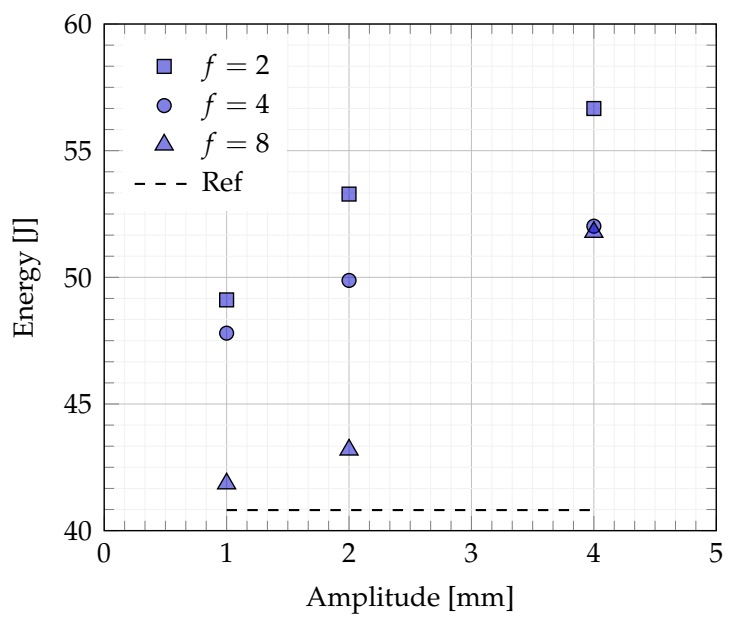

(a)

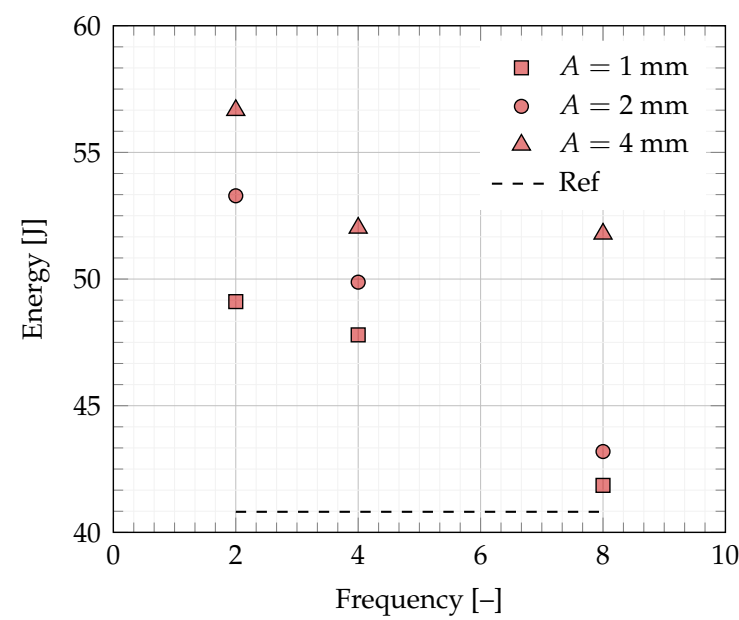

(b)

Figure 12. Energy absorption in optimised case, as function of the geometrical (a) amplitude and $(\mathbf{b})$ frequency.

These observed inverse trends in amplitude and frequency, as shown in Figure 13, allow for an optimal case to be identified, where the energy absorption is maximised. This optimal case is the one with higher amplitude $(A=4 \mathrm{~mm})$ and lower geometrical frequency $(f=2)$. For this particular case, the energy absorbed by each individual sandwich component are listed in Table 8 , together with the reference case. The overall performance of the sandwich plate improves by close to $40 \%$ in terms of energy absorption, and the skins and core are able to absorb more energy than in the reference case, as discussed above. The increase in absorbed energy is substantial in both skins. This can be explained by the higher velocity of the front skin and the cork core, which increase the bending effect, as can be seen from the corresponding maximum displacement. Additionally, the wavy configuration of the cork core induces a pattern of plastic strain distribution that further contributes to the increase in the energy absorption. The energy absorbed by the cork core increases by more than $20 \%$, as indicated in Table 8.

Table 8. Energy absorption in the reference and optimised case.

\begin{tabular}{llrrr}
\hline Case & & Reference & A4-f2 & Difference [\%] \\
\hline \multirow{4}{*}{ Absorbed energy } & Total & $40.64 \mathrm{~J}$ & $56.61 \mathrm{~J}$ & $15.97 \mathrm{~J}(39.3 \%)$ \\
& Cork & $32.61 \mathrm{~J}$ & $39.56 \mathrm{~J}$ & $6.95 \mathrm{~J}(21.3 \%)$ \\
& Front skin & $2.63 \mathrm{~J}$ & $6.00 \mathrm{~J}$ & $3.37 \mathrm{~J}(128.1 \%)$ \\
& Rear skin & $5.39 \mathrm{~J}$ & $11.03 \mathrm{~J}$ & $5.64 \mathrm{~J}(104.6 \%)$ \\
\hline \multirow{2}{*}{ Cork compression } & Maximum & 0.187 & 0.242 & $0.055(29.4 \%)$ \\
\hline \multirow{2}{*}{ Maximum displacement } & Front skin & $9.8 \mathrm{~mm}$ & $20.5 \mathrm{~mm}$ & $10.7 \mathrm{~mm}(109.2 \%)$ \\
& Rear skin & $8.3 \mathrm{~mm}$ & $12.1 \mathrm{~mm}$ & $3.8 \mathrm{~mm}(31.4 \%)$ \\
\hline
\end{tabular}

Figure 14 shows the evolution of the kinetic and internal energies for the individual components of the sandwich plate (skins and core), for both reference and optimum case. It can be clearly seen the different behaviour between both plates. The maximum kinetic energy reached by all components in the optimum case is clearly higher than the reference case. As it was previously said for Figure 11, this effect is especially observed for the front skin produced, because the sinusoidal shape delays the contact between the core and the rear skin. This change in the kinematic induces the higher internal energy absorbed by each individual component and, therefore, the sandwich itself for the optimum configuration compared with the reference. 


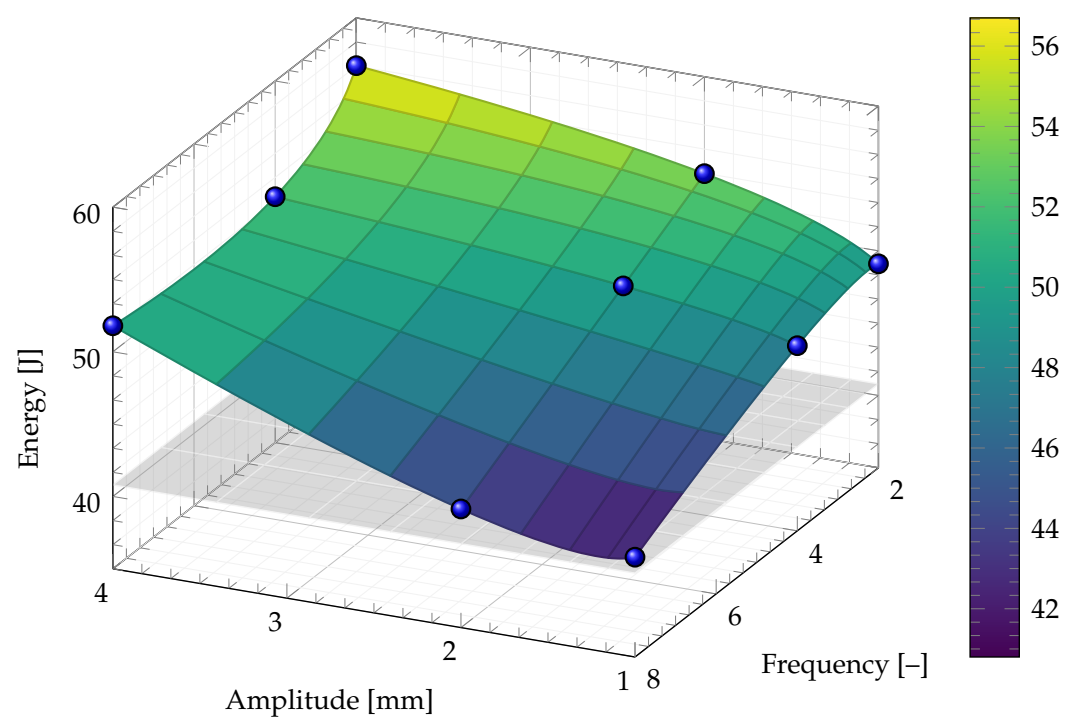

Figure 13. Biquadratic surface plot of the absorbed energy dependency on the geometrical amplitude and frequency (grey shaded surface is energy absorbed by reference plate).

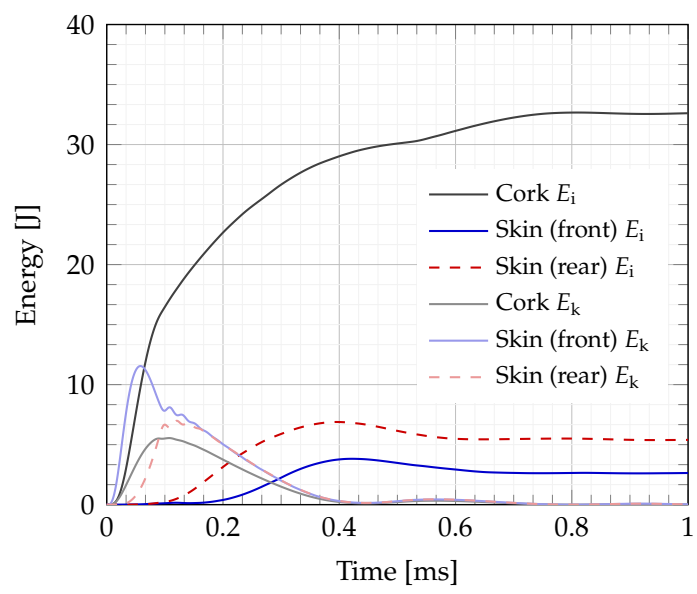

(a) Reference

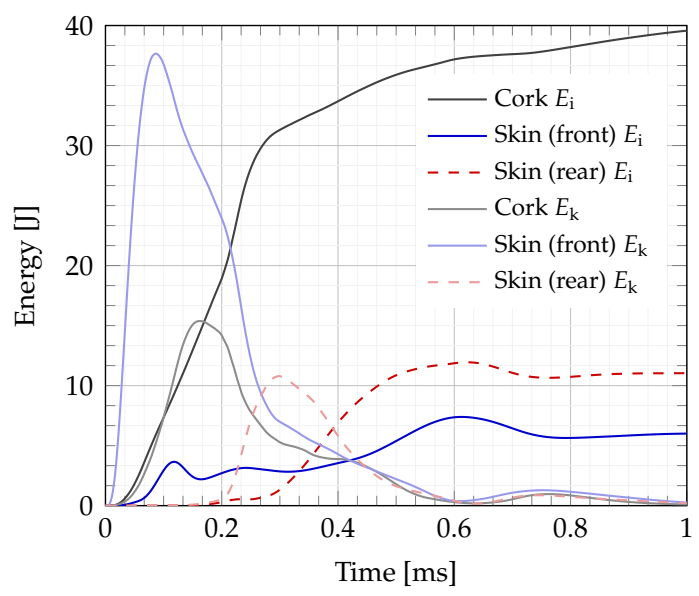

(b) A4-f2

Figure 14. Kinetic energy $E_{\mathrm{k}}$ and internal energy $E_{\mathrm{i}}$ for the individual components of the sandwich plate (skins and core), for simplified reference case and optimum (A4-f2) configuration.

\section{Conclusions}

A detailed numerical model is proposed for the analysis of the behaviour of aluminium skin and cork core sandwich plates subjected to blast loading. The model is developed, validated, and then used to optimise energy absorption in a blast protection sandwich structure. Two different methodologies were used for reproducing the blast load: the Arbitrary-Lagrangian-Eulerian (ALE) approach and the Load Blast Enhanced (LBE) method. Both are extensively validated by comparing the numerical results with the experimental observations reported by Sousa-Martins et al. [10]. The LBE model is then used to optimise the sandwich geometry and core configuration, with the aim of maximising the energy absorption capability of the structure, without compromising the areal density. The following main conclusions can be drawn from a detailed analysis and discussion of results:

- $\quad$ Both numerical models (ALE and LBE) are capable of accurately reproducing the blast load and its interaction with the structure. The ALE approach reproduces additional effects, such as the negative pressure phase, wave reflections, shadowed waves, etc. However, for the present case, it is shown that these have a minimal effect on the impulse and on the behaviour of the sandwich 
plate. Consequently, due to its significantly higher computational efficiency, the LBE model is used in the core optimisation analysis.

- The produced numerical analyses and results allow for a better understanding of the kinematic and mechanical behaviour of the sandwich structure during a blast event, increasing the knowledge of how this type of structure responds under such loading scenarios.

- The agglomerated cork core is responsible for most of the energy absorption and the main energy absorption mechanisms are cork compression and overall bending and stretching of the sandwich.

- The impulse transmitted to the ballistic pendulum, as determined by the numerical model, shows that the main contribution is the frontal rig, suggesting that confined blast experiments should be done to complement the analysis and isolate the impulse transmitted on to the specimen.

- An optimised sandwich plate topology is proposed with a wavy cork core. This is used to analyse the influence of geometrical parameters, such as the amplitude and the frequency of the shape, for constant areal density. Maximum energy absorption is achieved for the highest amplitude and lowest frequency, with close to $40 \%$ overall increase in energy absorption. The waviness of the core allows for an increase in the velocity of the front skin and core, leading to more prominent bending. The increased time of arrival of the wave to the rear skin also leads to an increase in the compression of the cork core.

Author Contributions: Conceptualization, J.P.-S., J.A.A.-G., D.V. and F.T.-D.; methodology, J.P.-S., J.A.A.-G.; software, J.P.-S., J.A.A.-G. and D.V.; validation, J.P.-S., J.A.A.-G. and D.V.; formal analysis, J.P.-S.; data curation, J.P.-S. and J.A.A.-G.; writing-original draft preparation, J.P.-S. and J.A.A.-G.; writing-review and editing, D.V. and F.T.-D.; visualization, J.P.-S., J.A.A.-G. and F.T.-D.; supervision, D.V. and F.T.-D.; project administration, J.P.-S.; funding acquisition, J.P.-S., J.A.A.-G., D.V. and F.T.-D. All authors have read and agree to the published version of the manuscript.

Funding: This research was funded by Ministerio de Economía y Competitividad, Gobierno de España grant number DPI2017-85073-R, and Universidad Carlos III of Madrid grant numbers 2013/00413/003 and 2014/00006/002. And the travel expenses were funded by Universidad Carlos III de Madrid grant number Programa propio de investigación-Convocatoria 2014 movilidad.

Conflicts of Interest: The authors declare no conflict of interest.The funders had no role in the design of the study; in the collection, analyses, or interpretation of data; in the writing of the manuscript, or in the decision to publish the results.

\section{References}

1. Yu, C.; Ortiz, M.; Rosakis, A. 3D modelling of impact failure in sandwich structures. In Fracture of Polymers, Composites and Adhesives II; Blackman, B., Pavan, A., Williams, J., Eds.; European Structural Integrity Society Elsevier: Amsterdam, The Netherlands, 2003; pp. 527-537.

2. Oterkus, E.; Diyaroglu, C.; Meo, D.D.; Allegri, G. Fracture modes, damage tolerance and failure mitigation in marine composites. In Marine Applications of Advanced Fibre-Reinforced Composites; Elsevier: Amsterdam, The Netherlands, 2016; pp. 79-102.

3. Nemat-Nasser, S.; Kang, W.; McGee, J.; Guo, W.G.; Isaacs, J. Experimental investigation of energy-absorption characteristics of components of sandwich structures. Int. J. Impact Eng. 2007, 34, 1119-1146. [CrossRef]

4. The European Parliament. Directive 2008/112/EC; The European Parliament: Brussel, Belgium, 2008.

5. Walsh, J.; Kim, H.I.; Suhr, J. Low velocity impact resistance and energy absorption of environmentally friendly expanded cork core-carbon fiber sandwich composites. Compos. Part A Appl. Sci. Manuf. 2017, 101, 290-296. [CrossRef]

6. Arteiro, A.; Reis, A.L.; Nóvoa, P.J.; Silva, L.F.; Zupan, M.; Marques, A.T. Low velocity impact and flexural performance of sandwich structures with cork and polymer foam cores. Ciênci Tecnol. Mater. 2013, 25, 79-84. [CrossRef]

7. Ptak, M.; Kaczynski, P.; Fernandes, F.; Alves de Sousa, R. Assessing impact velocity and temperature effects on crashworthiness properties of cork material. Int. J. Impact Eng. 2017, 106, 238-248. [CrossRef]

8. Sanchez-Saez, S.; Barbero, E.; Cirne, J. Experimental study of agglomerated-cork-cored structures subjected to ballistic impacts. Mater. Lett. 2011, 65, 2152-2154. [CrossRef] 
9. Sousa-Martins, J.; Kakogiannis, D.; Coghe, F.; Reymen, B.; Teixeira-Dias, F. Response of cork compounds subjected to impulsive blast loads: An experimental and numerical approach. Eur. Phys. J. 2012, 206, 61-70. [CrossRef]

10. Sousa-Martins, J.; Kakogiannis, D.; Coghe, F.; Reymen, B.; Teixeira-Dias, F. Behaviour of sandwich structures with cork compound cores subjected to blast waves. Eng. Struct. 2013, 46, 140-146. [CrossRef]

11. Hassan, M.; Guan, Z.; Cantwell, W.; Langdon, G.; Nurick, G. The influence of core density on the blast resistance of foam-based sandwich structures. Int. J. Impact Eng. 2012, 50, 9-16. [CrossRef]

12. Guan, Z.; Aktas, A.; Potluri, P.; Cantwell, W.; Langdon, G.; Nurick, G. The blast resistance of stitched sandwich panels. Int. J. Impact Eng. 2014, 65, 137-145. [CrossRef]

13. Nurick, G.; Langdon, G.; Chi, Y.; Jacob, N. Behaviour of sandwich panels subjected to intense air blast-Part 1: Experiments. Composite Struct. 2009, 91, 433-441. [CrossRef]

14. Karagiozova, D.; Nurick, G.; Langdon, G.; Yuen, S.C.K.; Chi, Y.; Bartle, S. Response of flexible sandwich-type panels to blast loading; ONR_Dynamic Failure and Durability. Compos. Sci. Technol. 2009, 69, 754-763. [CrossRef]

15. Reany, J.; Grenestedt, J.L. Corrugated skin in a foam core sandwich panel. Compos. Struct. 2009, 89, 345-355. [CrossRef]

16. Pimenta, S.; Robinson, P. Wavy-ply sandwich with composite skins and crushable core for ductility and energy absorption. Compos. Struct. 2014, 116, 364-376. [CrossRef]

17. Arronche, L.; Martínez, I.; La Saponara, V.; Ledesma, E. Finite Element Modeling and Experimental Characterization of Enhanced Hybrid Composite Structures for Improved Crashworthiness. J. Appl. Mech. 2013, 80, 050902. [CrossRef]

18. Livermore Software Technology Company. Keyword User's Manual. LS-DYNA R8.0. 2015. Available online: www.lstc.com (accessed on 28 July 2020)

19. Karagiozova, D.; Nurick, G.; Yuen, S.C.K. Energy absorption of aluminium alloy circular and square tubes under an axial explosive load. Thin Walled Struct. 2005, 43, 956-982. [CrossRef]

20. Sorger, G.; Wang, H.; Vilaça, P.; Santos, T.G. FSW of aluminum AA5754 to steel DX54 with innovative overlap joint. Welding World 2017, 61, 257-268. [CrossRef]

21. Wierzbicki, T.; Bao, Y.; Lee, Y.W.; Bai, Y. Calibration and evaluation of seven fracture models; A Special Issue in Honour of Professor Stephen R. Reid's 60th Birthday. Int. J. Mech. Sci. 2005, 47, 719-743. [CrossRef]

22. Zhou, J.; Gao, X.; Hayden, M.; Joyce, J.A. Modeling the ductile fracture behavior of an aluminum alloy 5083-H116 including the residual stress effect. Eng. Fracture Mech. 2012, 85, 103-116. [CrossRef]

23. Gao, X.; Zhang, T.; Hayden, M.; Roe, C. Effects of the stress state on plasticity and ductile failure of an aluminum 5083 alloy. Int. J. Plast. 2009, 25, 2366-2382. [CrossRef]

24. Zhou, J.; Hayden, M.; Gao, X. An investigation of the strain rate and temperature effects on the plastic flow stress and ductile failure strain of aluminum alloys 5083-H116, 6082-T6 and a 5183 weld metal. Proc. Inst. Mech. Eng. Part C J. Mech. Eng. Sci. 2013, 227, 883-895. [CrossRef]

25. Graham, S.M.; Zhang, T.; Gao, X.; Hayden, M. Development of a combined tension-torsion experiment for calibration of ductile fracture models under conditions of low triaxiality. Int. J. Mech. Sci. 2012, 54, 172-181. [CrossRef]

26. Gao, X.; Zhang, T.; Zhou, J.; Graham, S.M.; Hayden, M.; Roe, C. On stress-state dependent plasticity modeling: Significance of the hydrostatic stress, the third invariant of stress deviator and the non-associated flow rule. Int. J. Plast. 2011, 27, 217-231. [CrossRef]

27. Jackson, K.; Annett, M.; Fasanella, E.; Polanco, M. Material Model Evaluation of a Composite Honeycomb Energy Absorber; NASA: Washington, DC, USA, 2012.

28. Kiliçaslan, C.; Odac, K.; Tasdemirci, A.; Güden, M. Experimental Testing and Full and Homogenized Numerical Models of the Low Velocity and Dynamic Deformation of the Trapezoidal Aluminium Corrugated Core Sandwich. Strain 2014, 50, 236-249. [CrossRef]

29. Gameiro, C.P.; Cirne, J.; Gary, G. Experimental study of the quasi-static and dynamic behaviour of cork under compressive loading. J. Mater. Sci. 2007, 42, 4316-4324. [CrossRef]

30. Artero-Guerrero, J.; Pernas-Sánchez, J.; Teixeira-Dias, F. Blast wave dynamics: The influence of the shape of the explosive. J. Hazard. Mater. 2017, 331, 189-199. [CrossRef]

31. Pickering, E.; Yuen, S.C.K.; Nurick, G.; Haw, P. The response of quadrangular plates to buried charges. Int. J. Impact Eng. 2012, 49, 103-114. [CrossRef] 
32. Yuen, S.C.K.; Langdon, G.; Nurick, G.; Pickering, E.; Balden, V. Response of V-shape plates to localised blast load: Experiments and numerical simulation. Int. J. Impact Eng. 2012, 46, 97-109. [CrossRef]

33. Fallah, A.; Micallef, K.; Langdon, G.; Lee, W.; Curtis, P.; Louca, L. Dynamic response of Dyneema® HB26 plates to localised blast loading. Int. J. Impact Eng. 2014, 73, 91-100. [CrossRef]

34. Langdon, G.; Ozinsky, A.; Yuen, S.C.K. The response of partially confined right circular stainless steel cylinders to internal air-blast loading. Int. J. Impact Eng. 2014, 73, 1-14. [CrossRef]

35. Xia, Z.; Wang, X.; Fan, H.; Li, Y.; Jin, F. Blast resistance of metallic tube-core sandwich panels. Int. J. Impact Eng. 2016, 97, 10-28. [CrossRef]

36. Guo, Z.; Chen, W.; Zhang, Y.; Zou, H. Post fire blast-resistances of RPC-FST columns using improved Grigorian model. Int. J. Impact Eng. 2017, 107, 80-95. [CrossRef]

37. Remennikov, A.; Ngo, T.; Mohotti, D.; Uy, B.; Netherton, M. Reprint of: Experimental investigation and simplified modeling of response of steel plates subjected to close-in blast loading from spherical liquid explosive charges; Design and Analysis of Protective Structures 2015. Int. J. Impact Eng. 2017, 105, 1-12. [CrossRef]

38. Arora, H.; Linz, P.D.; Dear, J. Damage and deformation in composite sandwich panels exposed to multiple and single explosive blasts. Int. J. Impact Eng. 2017, 104, 95-106. [CrossRef]

39. Aune, V.; Valsamos, G.; Casadei, F.; Larcher, M.; Langseth, M.; Børvik, T. Numerical study on the structural response of blast-loaded thin aluminium and steel plates. Int. J. Impact Eng. 2017, 99, 131-144. [CrossRef]

40. Henchie, T.; Yuen, S.C.K.; Nurick, G.; Ranwaha, N.; Balden, V. The response of circular plates to repeated uniform blast loads: An experimental and numerical study; Advances in Impact Engineering: Selected papers from AEPA2012. Int. J. Impact Eng. 2014, 74, 36-45. [CrossRef]

41. Sahoo, D.; Guha, A.; Tewari, A.; Singh, R. Performance of Monolithic Plate and Layered Plates Under Blast Load; Plasticity and Impact Mechanics. Proc. Eng. 2017, 173, 1909-1917. [CrossRef]

42. Imbalzano, G.; Linforth, S.; Ngo, T.D.; Lee, P.V.S.; Tran, P. Blast resistance of auxetic and honeycomb sandwich panels: Comparisons and parametric designs. Compos. Struct. 2018, 183, 242-261. [CrossRef]

43. Kingery, C.N.; Bulmash, G. Airblast Parameters from TNT Spherical Air Bursts and Hemispherical Surface Bursts; ARBRL-TR-02555; US Army Armament Research and Development Center, Ballistic Research Laboratory: Aberdeen Proving Ground, MA, USA, 1984.

44. Huffington, N.; Ewing, W. Reflected Impulse Near Spherical Charges; Technical report BRL-TR-2678 AD-A160 797; Us Army Ballistic Research Laboratory Aberdeen Proving Ground: Harford County, MD, USA, 1985.

45. Dobratz, B.; Crawford, P. LLNL Explosives Handbook: Properties of Chemical Explosives and Explosive Simulants; Report UCRL-5299; Rev.2; Lawrence Livermore National Laboratory, University of California: Oakland, CA, USA, 1985.

46. Zakrisson, B.; Wikman, B.; Häggblad, H. Numerical simulations of blast loads and structural deformation from near-field explosions in air. Int. J. Impact Eng. 2011, 38, 597-612. [CrossRef]

47. Tabatabaei, Z.; Volz, J. A Comparison between Three Different Blast Methods in LS-DYNA: LBE, MM-ALE, Coupling of LBE and MM-ALE. In Proceedings of the 12th International LS-DYNA Users Conference, Detroit, MI, USA, 3-5 June 2012.

48. Rigby, S.E.; Tyas, A.; Bennett, T.; Fay, S.D.; Clarke, S.D.; Warren, J.A. A Numerical Investigation of Blast Loading and Clearing on Small Targets. Int. J. Protect. Struct. 2014, 5, 253-274. [CrossRef]

49. Herringbone-Bouligand CFRP structures: A new tailorable damage-tolerant solution for damage containment and reduced delaminations. Compos. Sci. Technol. 2020, 190, 108047. [CrossRef]

(C) 2020 by the authors. Licensee MDPI, Basel, Switzerland. This article is an open access article distributed under the terms and conditions of the Creative Commons Attribution (CC BY) license (http://creativecommons.org/licenses/by/4.0/). 